\title{
Study of Management of Retinoblastoma with Vitreous Seeds (Retrospective Study)
}

\author{
MAGDY M. EL-BARBARY, M.D.; AZZA M.A. SAID, M.D. and MONA K. EL-AWADY, M.Sc. \\ The Department of Ophthalmology, Faculty of Medicine, Ain Shams University
}

\begin{abstract}
Background: The response of retinoblastoma with vitreous seeds to the different modalities of treatment as regards tumor regression, vitreous seeds regression and eye salvage.

Aim of the Work: Study of the response of $\mathrm{Rb}$ with vitreous seeds to the different modalities of treatment as regards tumor regression, vitreous seeds regression and eye salvage.

Patients and methods: This is a retrospective observational study in which we collected the data from medical records of cases of retinoblastoma with vitreous seeds who were managed over ten years at Ocular Oncology Unit, Ophthalmology Department, Ain Shams University Hospitals in the period from January 2004 to June 2015 and followed-up for at least 12 months after the completion of treatment. Our study included 37 patients. Fourty-two eyes affected with retinoblastoma with vitreous seeds were divided into four groups according to the modality of treatment: Group (1): 15 eyes treated with chemoreduction \pm focal therapy (diode laser thermotherapy or cryotherapy), Group (2): 8 eyes treated with intravitreal chemotherapy, Group (3): 2 eyes treated with intra-arterial chemotherapy and Group (4): 17 eyes of treated with subTenon's Carboplatin. All eyes had received systemic chemotherapy as a primary treatment before these modalities of treatment.

Results: Our study showed that the rate of ocular salvage was the highest in group $4(52.9 \%)$ followed by group 1 $(40 \%)$, group $2(20 \%)$ and group $3(0.0 \%)$. There was a statistically significant difference between group 1 and group 4 as regards tumor number, tumor location, tumor base diameter, number of thermotherapy sessions as primary treatment, mean duration of follow-up and event free interval from last treatment.
\end{abstract}

Conclusion: Subtenon's Carboplatin, chemoreduction plus focal therapy, intravitreal chemotherapy and intra-arterial chemotherapy may be effective supplementary modalities of treatment that help in ocular salvage.

Key Words: Retinoblastoma - Subtenon's Carboplatin Chemoreduction plus focal therapy - Intravitreal chemotherapy - Intra-arterial chemotherapy.

Correspondence to: Dr. Magdy M. El-Barbary

The Department of Ophthalmology, Faculty of Medicine, Ain Shams University

\section{Introduction}

RENTINOBLASTOMA (Rb) is the most common primary ocular malignancy of childhood. There are two forms heritable and non heritable. Presentation is in the first few years of life, sometimes in the neonatal period. Early detection and prompt treatment can give cure rates up to $95 \%$ for intraocular tumors, but extraocular diseases carries a very high mortality. The diagnosis is essentially clinical and biopsy is contraindicated due to the risk of extraocular spread [1]

The presence of vitreous seeds has been recognized as a major risk factor for eye survival. Vitreous seeding is characterized by presence of tumor cells in the vitreous cavity. It may also appear during the treatment course (secondary) in eyes devoid of vitreous seeds at diagnosis. A possible iatrogenic component is present which is laser thermotherapy used for treatment. Another cause of secondary vitreous involvement is the sudden vitreous dispersion of large tumors shortly after the initiation of chemotherapy due to a necrotic disruption of the internal limiting membrane [2] .

There are several methods to manage intraocular $\mathrm{Rb}$. Focal (cryotherapy, laser photocoagulation, transpupillary thermotherapy, transcleral thermotherapy, and plaque brachytherapy), local (external beam radiotherapy, enucleation) and systemic (chemotherapy). While primary focal measures are mainly reserved for small tumors, local and systemic modalities are used to treat advanced $\mathrm{Rb}[3]$

Chemotherapy is the current promising method in management of $\mathrm{Rb}$. It can be delivered systemically, regionally or locally. Standard triple drug systemic chemotherapy (vincristine, etoposide and carboplatin) is most effective in tumors without associated subretinal fluid, subretinal seeds or vitreous seeds [4] 
Intra-arterial chemotherapy (IAC) has emerged as an important new modality for treating eyes with advanced intraocular Rb. Doses used for IAC have ranged between 3.0 and $7.5 \mathrm{mg}$ of Melphalan per treatment in primary cases and a multidrug regimen of Carboplatin, Melphalan and Topotecan in severe cases [ $\boldsymbol{s}$.

Intravitreal chemotherapy (IVC) injection has recently emerged as a potential new modality to salvage eyes with residual vitreous seeding after systemic or intra-arterial chemotherapy [6] .

Trans scleral delivery system of chemotherapeutic agents was in a small, impermeable refillable silicone reservoir that can be firmly attached to episclera with minimal invasive conjunctival surgery [7].

\section{Patients and Methods}

This is a retrospective observational study in which we studied data collected from medical records of cases of $\mathrm{Rb}$ with vitreous seeds who were managed over ten years at Ocular Oncology Unit, Ophthalmology Department, Ain Shams University Hospitals in the period from January 2004 to June 2015 and followed-up for at least 12 months after the completion of treatment.

Our study included 42 eyes of 37 patients. The eyes are divided into four groups according to the modality of treatment: Group (1): 15 eyes treated with chemoreduction \pm focal therapy, Group (2): 8 eyes treated with IVC, Group (3): 2 eyes treated with IAC and Group (4): 17 eyes of treated with subTenon's Carboplatin. All eyes had received systemic chemotherapy as a primary treatment before these modalities of treatment.

This study involved the previously diagnosed and treated $\mathrm{Rb}$ patients who were under followup.

Full medical history, Personal history includes name, age at time of presentation, sex, residency, positive family history for $\mathrm{Rb}$ and consanguinity and past history of previous investigations or modes of treatment.

In old cases, the patient charts either in the ophthalmology or radiotherapy department were reviewed with special attention to age at time of treatment, the mode and duration of treatment and the duration passed since interference.

Accurate diagnosis was performed for the cases, which included ophthalmological examination of the child was conducted under general anesthesia with full pupillary dilation.
External ocular examination of both eyes, intraocular pressure measurement using Schiotz indentation tonometer and fundus examination of both eyes was performed in all patients using indirect ophthalmoscope with scleral indentation.

Assessment of the mass color, location, size, numbers, overlying retinal detachment and subretinal fluid, presence of vitreous seeds (focal or diffuse) and determination of its class and subretinal seeds.

Fundus findings of both eyes were photographed for documentation and follow-up after therapy.

Radiological examination was essential for the confirmation of the diagnosis and measurement of the tumor dimensions using ocular ultrasonography and $\mathrm{CT}$ scans of brain and orbits.

Staging of the disease was done using international classification of $\mathrm{Rb}$.

\section{Results}

Our study included 42 eyes of 37 patients. The eyes were divided into four groups according to the modality of treatment: Group (1): 15 eyes treated with chemoreduction \pm focal therapy, Group (2): 8 eyes treated with IVC, Group (3): 2 eyes treated with IAC and Group (4): 17 eyes of treated with subTenon's Carboplatin. All eyes had received systemic chemotherapy as a primary treatment before these modalities of treatment.

The rate of ocular salvage was the highest in group $4(52.9 \%)$ followed by group $1(40 \%)$, group $2(20 \%)$ and group $3(0.0 \%)$. Fifteen eyes $(35.71 \%)$ with $\mathrm{Rb}$ with vitreous seeds were treated with chemoreduction plus focal therapy. Six eyes (40\%) were salvaged. Eight eyes (19.04\%) were treated with IVC of Melphalan. Ocular salvage occurred in one eye $(12.5 \%)$. Two eyes $(4.76 \%)$ were treated with IAC. Enucleation occurred in the two eyes $(100 \%)$. Seventeen eyes $(40.47 \%)$ were treated with subTenon's injection of Carboplatin. Nine eyes $(53 \%)$ were salvaged.

In (group 1), primary seeds were more than secondary seeds and primary diffuse seeds were the commonest while, in (group 4) secondary seeds were more common than primary seeds and secondary diffuse seeds were the commonest.

Ocular salvage was the highest in eyes affected by primary diffuse vitreous seeds $(50 \%)$ followed by primary focal seeds $(42.85 \%)$, secondary focal seeds $(36.36 \%)$ and secondary diffuse seeds (3 1.25\%). 
Table (1): The effect of the four treatment modalities on the rate of ocular salvage in relation to the groups of international classification of $\mathrm{Rb}$.

\begin{tabular}{lllll}
\hline Stage of Rb & $\begin{array}{c}\text { CRD+ } \\
\text { focalt } \\
\text { therapy }\end{array}$ & IVC & IAC & $\begin{array}{c}\text { Subtenon's } \\
\text { Carboplatin }\end{array}$ \\
\hline Group B: & & No. $20(47.61 \%)$ & \\
Salvaged & $1(20 \%)$ & $\begin{array}{l}1(20 \%) \\
(0.0 \%)\end{array}$ & $5(50.0 \%)$ \\
Not salvaged & $4(80 \%)$ & $4(80 \%)$ & $(0.0 \%)$ & $5(50.0 \%)$ \\
Total & 5 & 5 & 0 & 10 \\
Group C: & & No. $18(42.90 \%)$ & \\
Salvaged & $4(57.2 \%)$ & $0(0.0 \%)$ & $0(0.0 \%)$ & $4(66.7 \%)$ \\
Not salvaged & $3(42.8 \%)$ & $3(100 \%)$ & $2(100 \%)$ & $2(33.3 \%)$ \\
Total & 7 & 3 & 2 & 6 \\
Group D: & & \multicolumn{2}{c}{ No. $4(9.52 \%)$} & \\
Salvaged & $1(33.3 \%)$ & $0(0.0 \%)$ & $(0.0 \%)$ & $0(0.0 \%)$ \\
Not salvaged & $2(66.6 \%)$ & $0(0.0 \%)$ & $(0.0 \%)$ & $1(100 \%)$ \\
Total & 3 & 0 & 0 & 1 \\
\hline
\end{tabular}

Table (2): Comparison between group (1) and group (4) as regards tumor number. There was a statistically significant difference $(p$-value $=0.01)$ between the two groups. Tumor number was higher in group (4) than group (1).

\begin{tabular}{|c|c|c|c|c|c|c|c|c|c|}
\hline \multirow{2}{*}{ Groups } & \multicolumn{2}{|c|}{ One } & \multicolumn{2}{|c|}{ Two } & \multicolumn{2}{|c|}{ Three } & Four & \multirow{2}{*}{$=\mathrm{X} 2 *$} & \multirow{2}{*}{$\begin{array}{c}p- \\
\text { value }\end{array}$} \\
\hline & No. & $\% \mathrm{I}$ & No. & $\%$ & No. & $\%$ & No. \% & & \\
\hline 1 & 14 & 93.3 & 0 & 0 & 1 & 6.7 & O O & 12.20 & \\
\hline 4 & 6 & 35.3 & 74 & 1.2 & 31 & 7.6 & $15.9 \mathrm{~F}$ & $\begin{array}{c}\text { isher } \\
\text { exact }\end{array}$ & $0.01(\mathrm{~S})$ \\
\hline
\end{tabular}

Table (3): Comparison between group (1) and group (4) as regards the tumor location. There was a statistically significant difference $(p$-value $=0.05)$ between the two groups according to tumor location. $53.3 \%$ of tumors in group (1) and $88.2 \%$ of tumors in group (4) were $>3 \mathrm{~mm}$ from the fovea.

\begin{tabular}{|c|c|c|c|c|c|c|}
\hline \multirow[t]{2}{*}{ Groups } & \multicolumn{2}{|c|}{$\begin{array}{c}\leq 3 \mathrm{~mm} \text { from } \\
\text { fovea or } \\
\text { juxtapapillary }\end{array}$} & \multicolumn{2}{|c|}{$\begin{array}{c}>3 \mathrm{~mm} \text { from } \\
\text { the fovea }\end{array}$} & \multirow[t]{2}{*}{$\mathrm{X} 2 *$} & \multirow{2}{*}{$\begin{array}{c}p- \\
\text { value }\end{array}$} \\
\hline & No. & $\%$ & No. & $\%$ & & \\
\hline 1 & 7 & 46.7 & 8 & 53.3 & 4.80 & \multirow{2}{*}{$0.05(\mathrm{~S})$} \\
\hline 4 & 2 & 11.8 & 15 & 88.2 & Fisher exact & \\
\hline
\end{tabular}

Table (4): Comparison between group (1) and group (4) as regards tumor base diameter. There was a statistically significant difference $(p$-value $=0.01)$ between the two groups. Tumors with base diameter $\leq 10 \mathrm{~mm}$ was more in (group 4) while tumors with base diameter $>10 \mathrm{~mm}$ were higher in (group 1).

\begin{tabular}{|c|c|c|c|c|c|c|}
\hline \multirow{2}{*}{ Groups } & \multicolumn{2}{|c|}{$\begin{array}{l}\leq 10 \mathrm{~mm} \text { in base } \\
\text { diameter }\end{array}$} & \multicolumn{2}{|c|}{$\begin{array}{c}>10 \mathrm{~mm} \text { in base } \\
\text { diameter }\end{array}$} & \multirow[t]{2}{*}{$\mathrm{X} 2 *$} & \multirow{2}{*}{$\begin{array}{c}p- \\
\text { value }\end{array}$} \\
\hline & No. & $\%$ & No. & $\%$ & & \\
\hline 1 & 7 & 46.7 & 8 & 53.3 & 6.41 & $0.01(\mathrm{~S})$ \\
\hline 4 & 15 & 88.2 & 2 & 11.8 & & \\
\hline
\end{tabular}

Table (5): Comparison between group (1) and group (4) as regards type of vitreous seeds. There was a statistically significant difference $(p$-value $=0.03)$ between the two groups.

\begin{tabular}{|c|c|c|c|c|c|c|c|c|c|c|}
\hline \multirow{2}{*}{ Groups } & \multicolumn{2}{|c|}{$\begin{array}{l}1 \text { ry } \\
\text { Focal }\end{array}$} & \multicolumn{2}{|c|}{$\begin{array}{c}1 \text { ry } \\
\text { Diffuse }\end{array}$} & \multicolumn{2}{|c|}{$\begin{array}{c}2 \text { ry } \\
\text { Focal }\end{array}$} & \multicolumn{2}{|c|}{$\begin{array}{c}2 \text { ry } \\
\text { Diffuse }\end{array}$} & \multirow[t]{2}{*}{$\mathrm{X} 2 *$} & \multirow{2}{*}{$\begin{array}{c}p- \\
\text { value }\end{array}$} \\
\hline & No. & $\% \mathrm{I}$ & Jo. & $\% \mathrm{I}$ & Jo. & $\% \mathrm{I}$ & No. & $\%$ & & \\
\hline 1 & 4 & 26.7 & 5 & 33.3 & 4 & 26.7 & 2 & 13.3 & & \\
\hline 4 & 1 & 5.9 & 1 & 5.9 & 6 & 35.3 & 9 & 52.9 & 8.82 & $0.03(\mathrm{~S})$ \\
\hline
\end{tabular}

Table (6): Comparison between group (1) and group (4) as regards the mean event free interval from last treatment (years) $\pm \mathrm{SD}$. There was a statistically significant difference $(p$-value $=0.01)$ between the two groups being shorter in study group (4).

\begin{tabular}{cccc}
\hline Groups & Mean \pm SD & $t^{* *}$ & $p$-value \\
\hline 1 & $6.11 \pm 1.45$ & 3.81 & $0.01(\mathrm{~S})$ \\
4 & $3.20 \pm 2.32$ & & \\
\hline
\end{tabular}

Table (7): Comparison between group (1) and group (4) as regards the mean duration of follow-up (years) \pm SD. There was a highly statistically significant difference $(p$-value $=0.001)$ between the two groups. Mean duration of follow-up (years) \pm SD was higher in group 1 (7.28 \pm 1.88$)$ than in group $4(4.29 \pm 2.25)$.

\begin{tabular}{cccc}
\hline Groups & Mean \pm SD & $t^{*}$ & $p$-value \\
\hline 1 & $7.28 \pm 1.88$ & & \\
4 & $4.29 \pm 2.25$ & 3.72 & $0.001(\mathrm{HS})$ \\
\hline
\end{tabular}

Table (8): Rate of ocular salvage in each type of vitreous seeds in the study groups.

\begin{tabular}{|c|c|c|c|c|}
\hline $\begin{array}{c}\text { Type of } \\
\text { vitreous seeds }\end{array}$ & $\begin{array}{l}1 \text { ry } \\
\text { focal }\end{array}$ & $\begin{array}{c}\text { 1ry } \\
\text { diffuse }\end{array}$ & $\begin{array}{l}2 \text { ry } \\
\text { focal }\end{array}$ & $\begin{array}{l}2 \text { ry } \\
\text { diffuse }\end{array}$ \\
\hline Group B: & \multicolumn{4}{|c|}{ No. $20(47.61 \%)$} \\
\hline Salvaged & 0 & $1(50.0 \%)$ & $3(42.85 \%)$ & $4(36.36 \%)$ \\
\hline Not salvaged & 0 & $1(50.0 \%)$ & $4(57.14 \%)$ & $7(63.63 \%)$ \\
\hline Total & 0 & 2 & 7 & 11 \\
\hline Group C: & \multicolumn{4}{|c|}{ No. $18(42.90 \%)$} \\
\hline Salvaged & $3(42.8 \%)$ & $2(66.66 \%)$ & $1(33.33 \%)$ & $1(20 \%)$ \\
\hline Not salvaged & $4(57.2 \%$ & $1(33.33 \%)$ & $2(66.66 \%)$ & $4(80 \%)$ \\
\hline Total & 7 & 3 & 3 & 5 \\
\hline Group D: & \multicolumn{4}{|c|}{ No. $4(9.52 \%)$} \\
\hline Salvaged & 0 & $1(33.33 \%)$ & 0 & 0 \\
\hline Not salvaged & & $2(66.67 \%)$ & $1(100 \%)$ & 0 \\
\hline Total & 0 & 3 & 1 & 0 \\
\hline
\end{tabular}

\section{Discussion}

Our study showed that the rate of ocular salvage was the highest in group $4(52.9 \%)$ followed by group $1(40 \%)$, group $2(20 \%)$ and group $3(0.0 \%)$.

Our study showed that fifteen eyes $(35.71 \%)$ with $\mathrm{Rb}$ with vitreous seeds were treated with 
chemoreduction plus focal therapy and six eyes (40\%) were salvaged. Eight eyes $(19.04 \%)$ were treated with IVC of Melphalan and one eye (12.5\%) was salvaged. Two eyes $(4.76 \%)$ were group C and treated with IAC and the two eyes (100\%) were enucleated. Seventeen eyes $(40.47 \%)$ were treated with subTenon's injection of Carboplatin and nine eyes (53\%) were salvaged.

Manjandavida et al., [4] reported that eye salvage was $53 \%$ with primary chemotherapy and focal treatment with or without periocular carboplatin for treatment of $\mathrm{Rb}$ with vitreous seeds. $95 \%$ in group C, $85 \%$ in group D. The percentage of ocular salvage was close to our resulrs.

Qian et al., [8] reported in their study on 14 eyes $(35 \%)$ were group A, 9 eyes $(22.5 \%)$ were group B, 4 eyes (10\%) were group C and 10 eyes $(25 \%)$ were group $\mathrm{D}$ treated with the combined therapy included chemoreduction with local cryotherapy and/or transpupillary thermotherapy (TTT) for management of $\mathrm{Rb}$ with vitreous and/or subretinal seeds. The average follow-up duration was 38 months. The overall globe preservation rate was $75 \%$ and was $100 \%$ in group A, $100 \%$ in group B, $75 \%$ in group C, $40 \%$ in group $\mathrm{D}$. The percentage of ocular salvage was higher than in our study may be due to variation in number of patients which was higher than in their studies, mixture of chemotherapeutic regimens and possibility of resistance to the administrated chemotherapeutic agents.

Kaneko and Suzuki [9] treated 41 eyes with 8ug intravitreal Melphalan and reported the globe salvage in $51 \%$ cases.

Shields et al., [10] reported in their study on 11 eyes with recurrent vitreous seeds after systemic chemotherapy. After intravitreal injection of 20$30 \mathrm{tg}$ Melphalan, there was $100 \%$ seeds control, $100 \%$ eye salvage and no recurrence at 9 months mean follow-up.

Munier et al., [11] reported complete regression of vitreous seeds using intravitreal Melphalan with an average of 5.3 total weekly injections and globe salvage in $87 \%$.

The results of the present study were incomparable with the previous studies concerned with IVC in Rb with vitreous seeding may be due to few number of injections in each eye, failure of continuation of follow-up and variation of dose of chemotherapy (we used $8 \mu \mathrm{g}$, others used higher doses of chemotherapeutic agent up to $50 \mu \mathrm{g}$ ).
Abramson et al., [12] reported a success rate of $66 \%$ of eyes with recurrent vitreous seeding treated by intra-arterial chemotherapy with Melphalan.

Shields et al., [13] reported that IAC led to globe salvage in $67 \%$ of the eyes with $\mathrm{Rb}$ with vitreous seeds. Eyes classified as group C or D showed $100 \%$ globe salvage. Of the four eyes managed with IAC as secondary treatment, globe savages were achieved in $50 \%$.

Shields et al., [14] reported in their study on 40 patients with advanced $\mathrm{Rb}$. The IAC was given for recurrent $\mathrm{Rb}$ and/or subretinal/vitreous seeds in 13 eyes $(93 \%)$ and for persistent viable $\mathrm{Rb}$ in one eye $(7 \%)$. After primary intravenous chemotherapy plus secondary IAC, globe salvage was achieved in 8 patients $(57 \%)$ at mean 2 years follow-up.

The percentage of ocular salvage of eyes with $\mathrm{Rb}$ with vitreous seeds treated with IAC was higher in comparison to the present study. This may be due to high coast. Another reason is occurance of early vasospasm of ophthalmic artery during injection.

Manjandavida et al., [4] reported that 73 eyes with diffuse vitreous seeds received a $15-\mathrm{mg}$ subTenon's Carboplatin injection (range, $1-13 \mathrm{mg}$; median, $6 \mathrm{mg}$ ). In all, 20 eyes (95\%) in group C and 34 eyes $(85 \%)$ in group D were salvaged. Of 77 eyes that were salvaged, 24 of 33 chemotherapy failures $(73 \%)$ regressed with EBR. Factors predicting tumor regression and eye salvage were bilateral $\mathrm{Rb}$ and absence of subretinal fluid. Factors predicting vitreous seed regression were absence of subretinal fluid and subretinal seeds.

Ocular salvage in this study was higher in comparison to the present study which may be due to small number of cases in the present study.

Marr et al., [15] reported in their study on 33 eyes of $\mathrm{Rb}$ with vitreous seeds that were followed for 7-148 months following initiation of periocular injections of Carboplatin that 13 eyes (39\%) have avoided enucleation. Twenty eyes were enucleated for disease progression at a mean time of 15 months post initiation of periocular carboplatin.

The results of their study as regards percentage of ocular salvage after treatment of $\mathrm{Rb}$ with vitreous seeds using subTenon's Carboplatin injection was similar to the results of the present study that achieved an ocular salvage of $41.2 \%$.

Although there was statistically significant difference between group (1) and group (4) as 
regards tumor number, tumor location, tumor base diameter, type of vitreous seeds, number of thermotherapy sessions as primary treatment and event free interval from last treatment, there was no difference as regards ocular salvage between the two groups as it was $40 \%$ in group (1) and $52 \%$ in group (4). This may be due to smaller number of cases in the present study.

Ocular salvage was higher in eyes of $\mathrm{Rb}$ with primary diffuse vitreous seeds $(50 \%)$ followed by primary focal $(42.8 \%)$, secondary focal $(36.3 \%)$ and secondary diffuse (3 1.2\%).

Primary diffuse vitreous seeds has the best prognosis while secondary diffuse has the worst prognosis.

\section{References}

1- PARULEKAR M.V.: Rethionblastoma. Current treatment and future direction. Early. Human. development, 86: 619-625, 2010.

2- GOMBOS D.S., CAUCHI P.A. and HUNGERFORD J.L.: Vitreous relapse following primary chemotherapy for retinoblastoma: Is adjuvant diode laser a risk factor? Br. J. Ophthalmol., 90: 1168-1172, 2006.

3- PANDEY A.N.: Retinoblastoma: An overview. Saudi. J. Ophthalmol., 28: 3 10-3 15, 2014.

4- MANJANDAVIDA F.P., HONAVAR S.G., REDDY V.A.P and KHANNA R.: Management and outcome of retinoblastoma with vitreous seeds. Ophthalmology, 121: 517524, 2014

5- ABRAMSON D.H., GOBIN Y.P. and MARR B.P. : Intraarterial chemotherapy for retinoblastoma. Ophthalmology, 119 (8): 1720-1721, 2012 a.

6- KARCIOGLU Z.A.: Fine needle aspiration biopsy (FNAB) for retinoblastoma. Retina, 22 (6): 707-710, 2002.

7- CARVALHO PRA, KRAUSSE ML and MURPHREE
$\mathrm{AL}$ : Delivery from episcleral exoplants. Invest. Ophthalmol. Vis. Sci., 47 (10): 45329, 2006.

8- QIAN J., XUE K., GAO Y.J., YUAN Y.F., SHAN H.D. and BI Y.W. : Clinical therapeutic efficiency of chemoreduction and local therapy for children with retinoblastoma. [Zhonghua yan ke za zhi] Chinese journal of ophthalmology, 46 (4): 312-316, 2010.

9- KANEKO A. and SUZUKI S.: Eye-preservation treatment of retinoblastoma with vitreous seeding. Jpn. J. Clin. Oncol., 33: 601-607, 2003.

10- SHIELDS C.L., MANJANDAVIDA F.P., LALLY S.E., PIERETTI G., AREPALLI S.A., CAYWOOD E.H., PASCAL JABBOUR P. and SHIELDS J.A.: Intra-arterial Chemotherapy for Retinoblastoma in 70 Eyes Outcomes Based on the International classification of retinoblastoma. Ophthalmology, 121: 1453-1460, 2014.

11- MUNIER F.L., GAILLARD M.C., BALMER A., SOLIMAN S., PODILSKY G., MOULIN A.P. and POPOVIC M.B.: Intravitreal chemotherapy for vitreous disease in retinoblastoma revisited: From prohibition to conditional indications. Br. J. Ophthalmol., 96: 1078-1083, 2012.

12- ABRAMSON D., MARR B. and DUNKEL I.: Intraarterial chemotherapy for retinoblastoma eyes with vitreous and/or subretinal seeding. Br. J. Ophthalmol., 96: 499 502,2012

13- SHIELDS C.L., BIANCIOTTO C.G., JABBOUR P., RAMASUBRAMANIAN A., LALLY S.E. and GRIFFIN G.C.: Intra-arterial chemotherapy for retinoblas-toma: report No. 1, control of retinal tumors, subretinal seeds and vitreous seeds. Arch. Ophthalmol., 129 (11): 13991406, 2011.

14- SHIELDS C.L., FULCO F.M., ARIAS J.D., ALARCON C., PELLEGRINI M., RISHI P, KALIKI P., BIANCIOTTO C.G. and SHIELDS J.A.: Retinoblastoma frontiers with intravenous, intra-arterial, periocular, and intravitreal chemotherapy Eye (Lond), 27 (2): 253-264, 2013.

15-MARR B.P., DUNKEL I.J., LINKER A. and ABRAMSON D.H.: Periocular carboplatin for retinoblastoma: longterm report (12 years) on efficacy and toxicity. Br. J. Ophthalmol., 96: 881- 883, 2012. 


\section{دراسة استرجاعية لطرق علاج ورم الشبكية الخبيث لدى الأطفال}

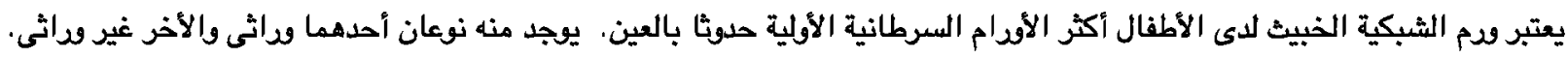

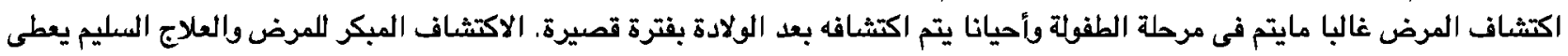

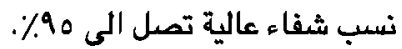

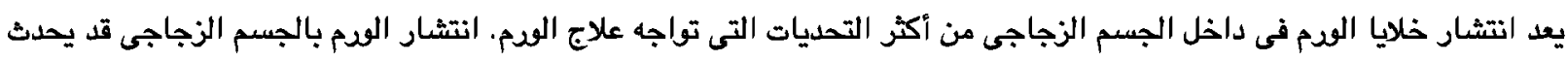
أثناء العلاج خاصة باليز الحرارى أو قد يحدث خلال فترة قصيرة من بدء العناء العلاج الكيميائى.

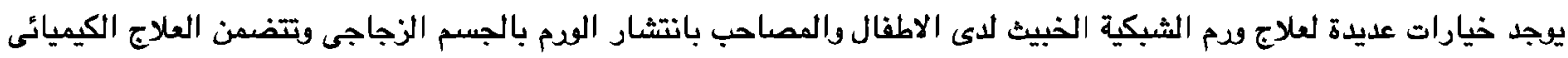

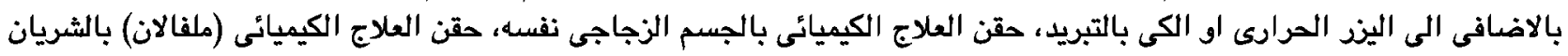

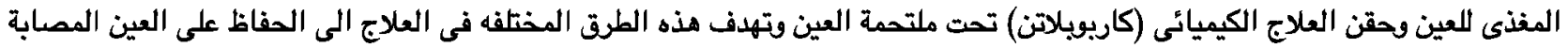

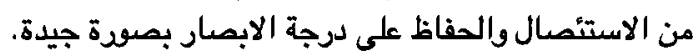
كان الهدف من هذه الدراسة هو توضيح الاتجاهات الحديثة فى علاج ودم الشبكية الخبيث لدى الأطفال والمصاحب بانتشار الورم بالجسم

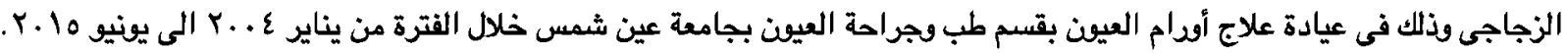

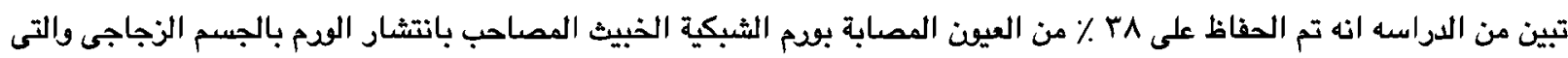

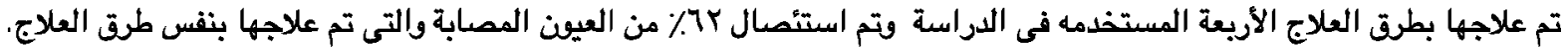

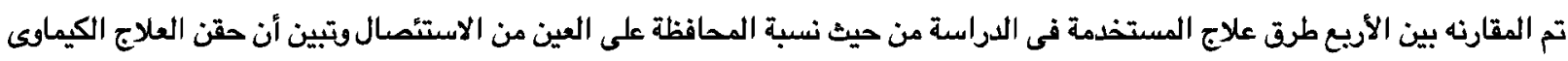

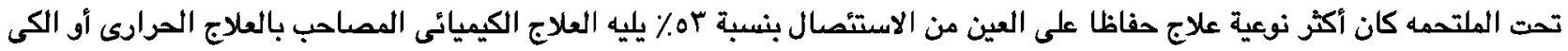

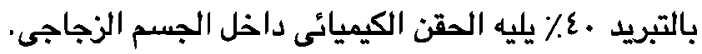

